\title{
Ancient times table hidden in Chinese bamboo strips
}

The 2,300-year-old matrix is the world's oldest decimal multiplication table.

Jane Qiu

07 January 2014

From a few fragments out of a collection of 23-century-old bamboo strips, historians have pieced together what they say is the world's oldest example of a multiplication table in base 10 .

Five years ago, Tsinghua University in Beijing received a donation of nearly 2,500 bamboo strips. Muddy, smelly and teeming with mould, the strips probably originated from the illegal excavation of a tomb, and the donor had purchased them at a Hong Kong market.

Researchers at Tsinghua carbon-dated the materials to around $305 \mathrm{bc}$, during the Warring States period before the unification of China.

Each strip was about 7 to 12 millimetres wide and up to half a metre long, and had a vertical line of ancient Chinese calligraphy painted on it in black ink. Historians realized that the bamboo pieces constituted 65 ancient texts and recognized them to be among the most important artefacts from the period.

"The strips were all mixed up because the strings that used to tie each manuscript together to form a scroll had long decayed," says Li Junming, a historian and palaeographer at Tsinghua. Some pieces were broken, others missing, he adds: to decipher the texts was "like putting together a jigsaw puzzle".

But "21 bamboo strips stand out from the rest as they contain only numbers, written in the style of ancient Chinese", says Feng Lisheng, a historian of mathematics at Tsinghua.

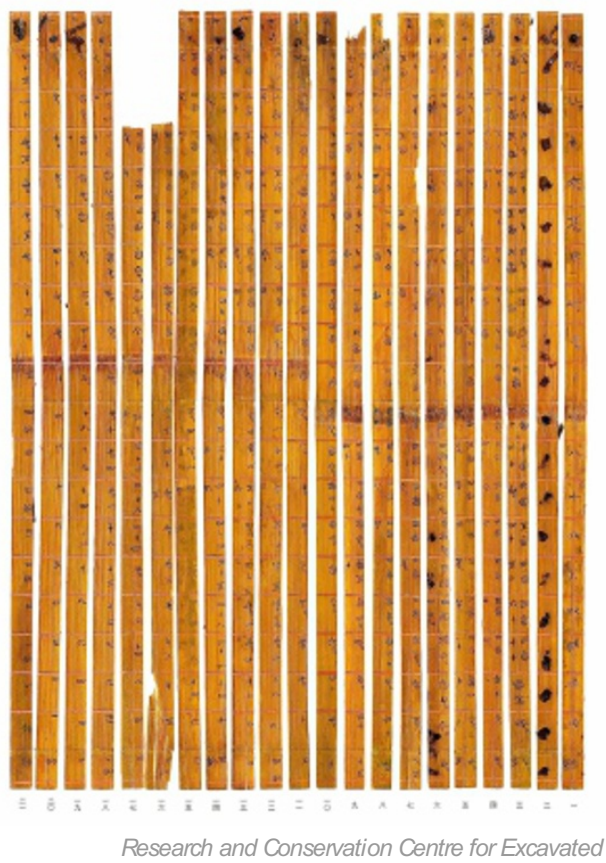

Text/Tsinghua Univ.

When assembled in the correct order, calligraphied bamboo strips from around $305 \mathrm{bc}$ revealed a table for multiplying numbers up to 99.5 .

Those 21 strips turned out to be a multiplication table, Feng and his colleagues announced in Beijing today during the presentation of the fourth volume of annotated transcriptions of the Tsinghua collection.

\section{Times tables}

When the strips are arranged properly, says Feng, a matrix structure emerges. The top row and the rightmost column contain, arranged from right to left and from top to bottom respectively, the same 19 numbers: 0.5 ; the integers from 1 to 9 ; and multiples of 10 from 10 to 90 .

As in a modern multiplication table, the entries at the intersection of each row and column in the matrix provide the results of multiplying the corresponding numbers. The table can also help users to multiply any whole or half integer between 0.5 and 99.5 . Numbers that are not directly represented, says Feng, first have to be converted into a series of additions. For instance, $22.5 \times 35.5$ can be broken up into $(20+$ 


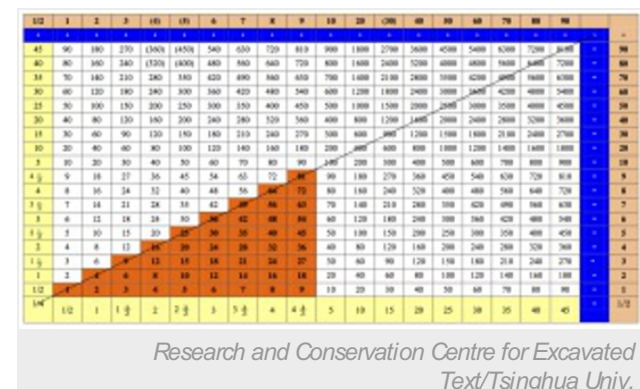

A translation of the oldest known decimal multiplication table.

$2+0.5) \times(30+5+0.5)$. That gives 9 separate multiplications $(20 \times 30,20 \times 5,20 \times 0.5,2$

$\times 30$, and so on), each of which can be read off the table. The final result can be obtained by adding up the answers. "It's effectively an ancient calculator," says Li.

The researchers suspect that officials used the multiplication table to calculate surface area of land, yields of crops and the amounts of taxes owed. "We can even use the matrix to do divisions and square roots," says Feng. "But we can't be sure that such complicated tasks were performed at the time."

"Such an elaborate multiplication matrix is absolutely

ㄱ unique in Chinese history," says Feng. The oldest previously known Chinese times tables, dating to the Qin

Dynasty between 221 and 206 bc, were in the form of a series of short sentences such as "six eights beget forty-eight" and capable of only much simpler multiplications. The ancient Babylonians possessed multiplication tables some 4,000 years ago, but theirs were in a base-60, rather than base-10 (decimal), system. The earliest-known European multiplication table dates back to the Renaissance.

"The discovery is of extraordinary interest," says Joseph Dauben, a maths historian at City University of New York. "It's the earliest artefact of a decimal multiplication table in the world."

It "certainly shows that a highly sophisticated arithmetic had been established for both theoretical and commercial purposes by the Warring States period in ancient China," he adds. This was just before Qin Shi Huang, China's first emperor, united the country; he subsequently ordered book burnings and banned private libraries in an attempt to reshape the country's intellectual tradition.

Nature I doi:10.1038/nature.2014.14482

\section{SPRINGER NATURE}

